\title{
Middle Ultraviolet Solar Spectral Irradiance Measurements, 1985-1992, from the SBUV/2 and SSBUV Instruments
}

\author{
By R I HARD P. CEBULA ${ }^{1}$, ERNESTHILSENRAT H \\ AND MATTHE T T. DELA N D \\ ${ }^{1}$ Hughes STX Corporation, Greenbelt, MD 20770, USA \\ ${ }^{2}$ NASA/Goddard Space Flight Center, Code 916, Greenbelt, MD 20771, USA
}

Solar spectral irradiance measurements from the NOAA-9 and NOAA-11 SBUV/2 instruments and SSBUV are presented and compared. Inter-instrument solar spectral irradiance differences on the order of $5-10 \%$ are observed. Internal comparisons of the SBUV/2 solar data suggest instrument sensitivity changes ranging from less than $1 \%$ per year near $400 \mathrm{~nm}$ to approximately $5 \%$ per year near $200 \mathrm{~nm}$.

The mission-to-mission accuracy of the SSBUV solar spectral irradiance measurements is better than $\pm 2 \%$. Initial results of our investigation into the feasibility of using SSBUV data to maintain the long-term calibration of the SBUV $/ 2$ instruments for solar spectral irradiance monitoring are reviewed.

\section{Introduction}

A data set whose length is longer than a single solar cycle and which accurately characterizes both short-term and long-term ultraviolet (UV) solar change is needed in order to understand the role of solar UV variations on observed stratospheric ozone trends. Daily solar spectral irradiance measurements have been made in the region 160 to 405 $\mathrm{nm}$ at $1 \mathrm{~nm}$ resolution by the Solar Backscatter Ultraviolet model 2 (SBUV/2) instruments on the NOAA-9 and NOAA-11 operational satellites since March 1985. These instruments, whose primary objective is to monitor long-term changes in stratospheric ozone, continue the solar irradiance measurements made from 1978 through 1987 by the Nimbus-7 SBUV instrument (Schlesinger \& Cebula 1992). The first SBUV/2 instrument was launched onboard the NOAA-9 satellite in December 1984 and began solar measurements in March 1985. The initial, or "Day 1", NOAA-9 SBUV/2 solar spectrum is shown in Figure 1. NOAA-9 data from March 1985 through January 1993 were processed using a simplified algorithm which assumes constant instrument sensitivity. Annual comparisons of NOAA-9 solar measurements to the Day 1 measurement are shown in Figure 2. These data were not corrected for long-term solar irradiance change. The $\mathrm{Mg}$ II core-to-wing proxy index of solar activity indicates that solar activity was at a minimum and roughly constant between March 1985 and March 1987, began to increase in spring 1987, and increased more rapidly starting in early 1988 (Donnelly 1990; Cebula et al. 1992). As measured by the $\mathrm{Mg}$ II index, solar activity was approximately $8 \%$ higher in 1989-1990 than in spring 1985. During the first two years operation, when the mean solar UV output was nearly constant, the observed instrument solar irradiance output changes arise solely due to instrument change. The data indicate that the instrument's sensitivity decreased by roughly $1.5 \%$ at $400 \mathrm{~nm}$ to as much as approximately $11 \%$ near $200 \mathrm{~nm}$ over this period. The rate of sensitivity decrease apparently slowed in the third year of operation, especially shortward of roughly $260 \mathrm{~nm}$. This apparent decline in the instrument degradation rate is attributable to an increase in the solar irradiance offsetting the continued instrument throughput decrease. DeLand \& Cebula (1993) have 


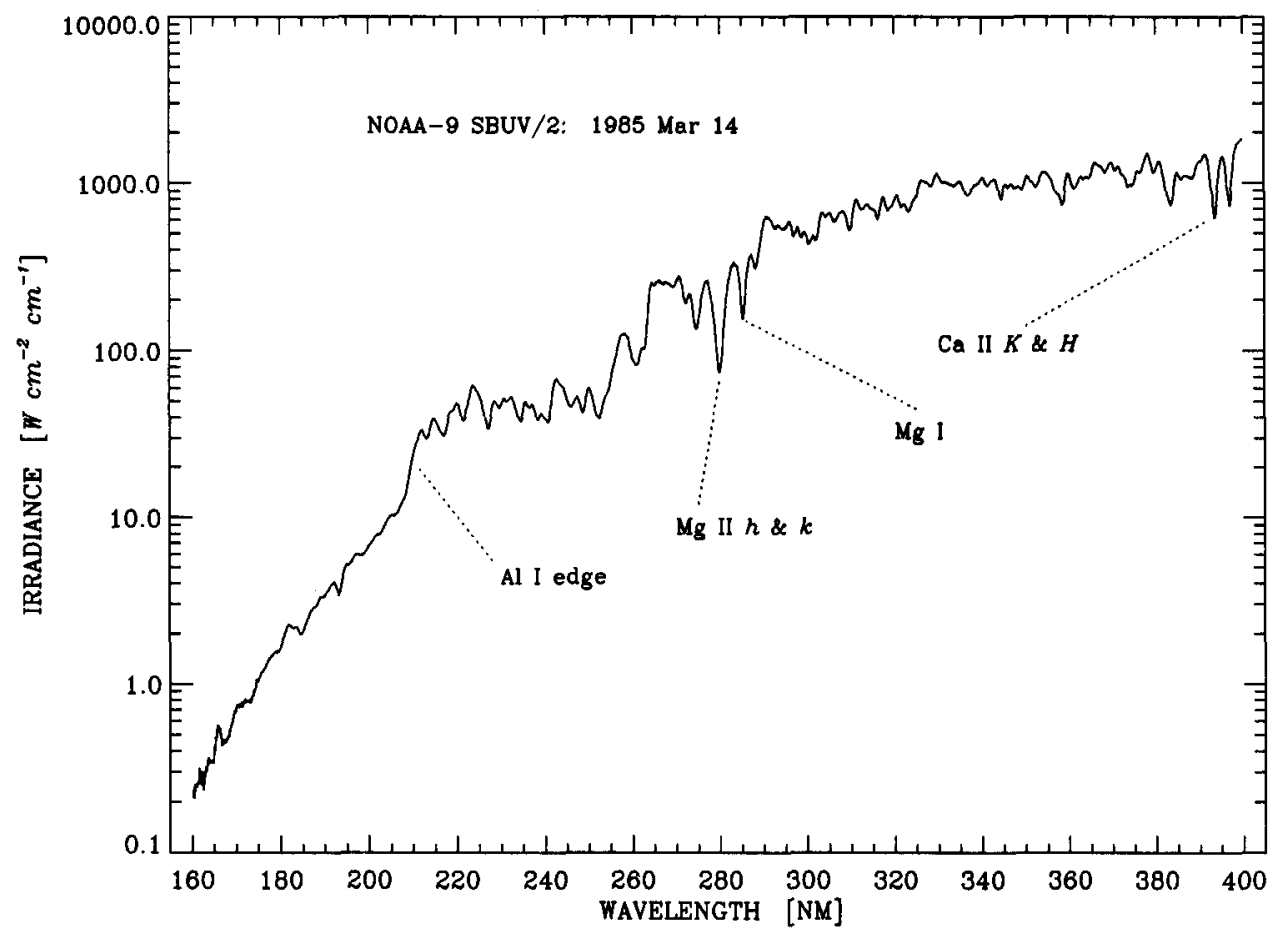

FIgURE 1. NOAA-9 SBUV/2 "Day 1" solar spectral irradiance.

estimated long-term solar spectral irradiance variations by scaling the $\mathrm{Mg}$ II index to other UV wavelengths. Using their methodology, we derive an approximate $9 \%$ increase in the solar irradiance at $200 \mathrm{~nm}$. Correcting for solar change, we conclude that the instrument's sensitivity continued to decline at a mean rate of 4-5\%/yr near $200 \mathrm{~nm}$.

The SBUV $/ 2$ instruments include an onboard calibration system in order to assess time-dependent diffuser reflectance changes in order to correctly derive long-term ozone amounts. Unfortunately, the NOAA-9 SBUV/2's system failed shortly after launch (Frederick et al. 1986). The second SBUV/2 instrument was launched onboard the NOAA-11 satellite in September 1988 and has been making daily solar spectral irradiance measurements from February 1989 through the present. The onboard calibration system was redesigned for the NOAA-11 instrument, and the resulting data have proven highly useful in monitoring long-term diffuser plate degradation (Weiss et al. 1993). The NOAA-11 SBUV/2 solar data presented here incorporate a correction for diffuser degradation, a recently derived inflight goniometry that is a $1-2 \%$ improvement on the previously used preflight goniometry, and an updated correction for photomultiplier tube change. The largest of these changes is the diffuser degradation correction, which ranges from roughly $0.4 \% / \mathrm{yr}$ near $400 \mathrm{~nm}$ to $1.7 \% / \mathrm{yr}$ near $160 \mathrm{~nm}$. In addition, the absolute radiometric calibration of the NOAA-11 instrument has recently been revised to correct for the effects of an error in the current setting of the spectral irradiance standard used during the calibration. This adjustment ranges from approximately $2.7 \%$ at $400 \mathrm{~nm}$ to $5.5 \%$ near 160 $\mathrm{nm}$. The calibration of the NOAA-9 instrument contains a corresponding error, however a revised calibration is not yet available. As a first approximation the NOAA-9 data presented here were corrected using the NOAA-11 wavelength dependent adjustment factor. 


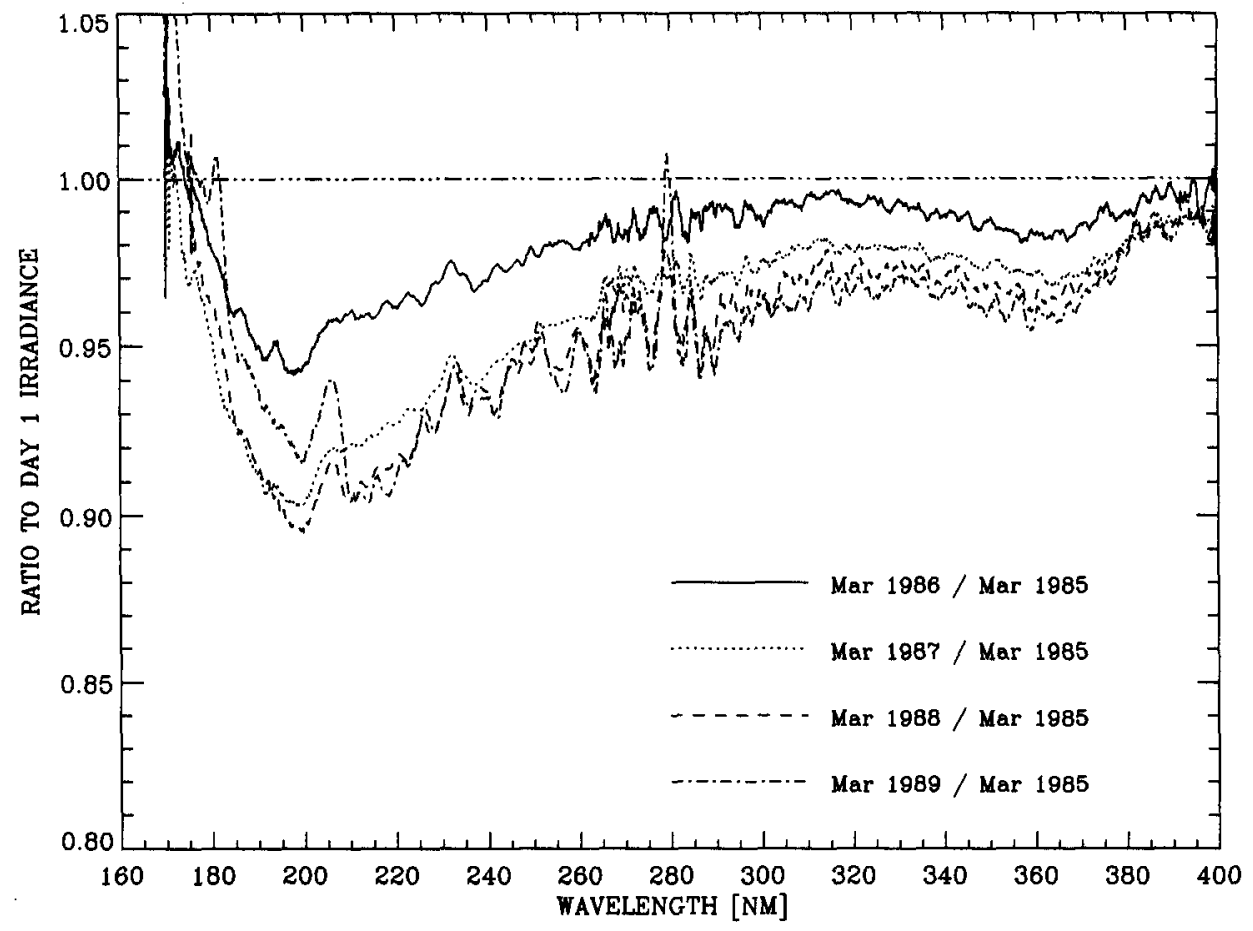

Figure 2. Annual comparisons of NOAA-9 SBUV/2 solar spectral irradiance measurements to the initial measurement.

The SBUV/2 irradiances presented herein replace the data previously presented (Cebula et al. 1991; Cebula \& DeLand 1992).

Figure 3 presents annual comparisons of the NOAA-11 SBUV/2 solar spectral irradiance output to the Day 1 irradiance. Using the technique of DeLand \& Cebula (1993), we estimate that from February 1989 through February 1992 the average solar output varied by $2 \%$ or less between 160 and $200 \mathrm{~nm}$, approximately $1 \%$ near $200 \mathrm{~nm}$, roughly $0.5 \%$ between 210 and $260 \mathrm{~nm}$, and less than $0.2 \%$ longward of $260 \mathrm{~nm}$. Consequently, Figure 3 provides a measure of long-term NOAA-11 instrument change, which is seen to range from less than $0.5 \% / \mathrm{yr}$ near $400 \mathrm{~nm}$ to roughly $5 \% / \mathrm{yr}$ near $200 \mathrm{~nm}$. Thus, the rate of sensitivity decrease of the NOAA-11 instrument optics alone is comparable to the rate of NOAA-9 instrument optics plus diffuser reflectivity change.

The SBUV/2 onboard calibration system only provides data on one element of the optical system, with no provision for the end-to-end calibration required for accurate longterm solar irradiance observations. Hence, alternate methods must be used to maintain the calibration of the SBUV/2 instruments. The Shuttle SBUV (SSBUV) experiment provides one such method. SSBUV is making middle UV solar irradiance measurements on a decade-long time scale with an instrument that is calibrated preflight, in-flight, and post-flight (Hilsenrath et al. 1988). The SSBUV instrument was the engineering model of the SBUV/2-series and, except for replacement of the reflection diffuser with a transmission diffuser to facilitate solar measurements from the Space Shuttle, is optically identical to the satellite instruments.

SSBUV has flown five times during the period October 1989 through April 1993, and four additional SSBUV missions are scheduled through at least 1997. 


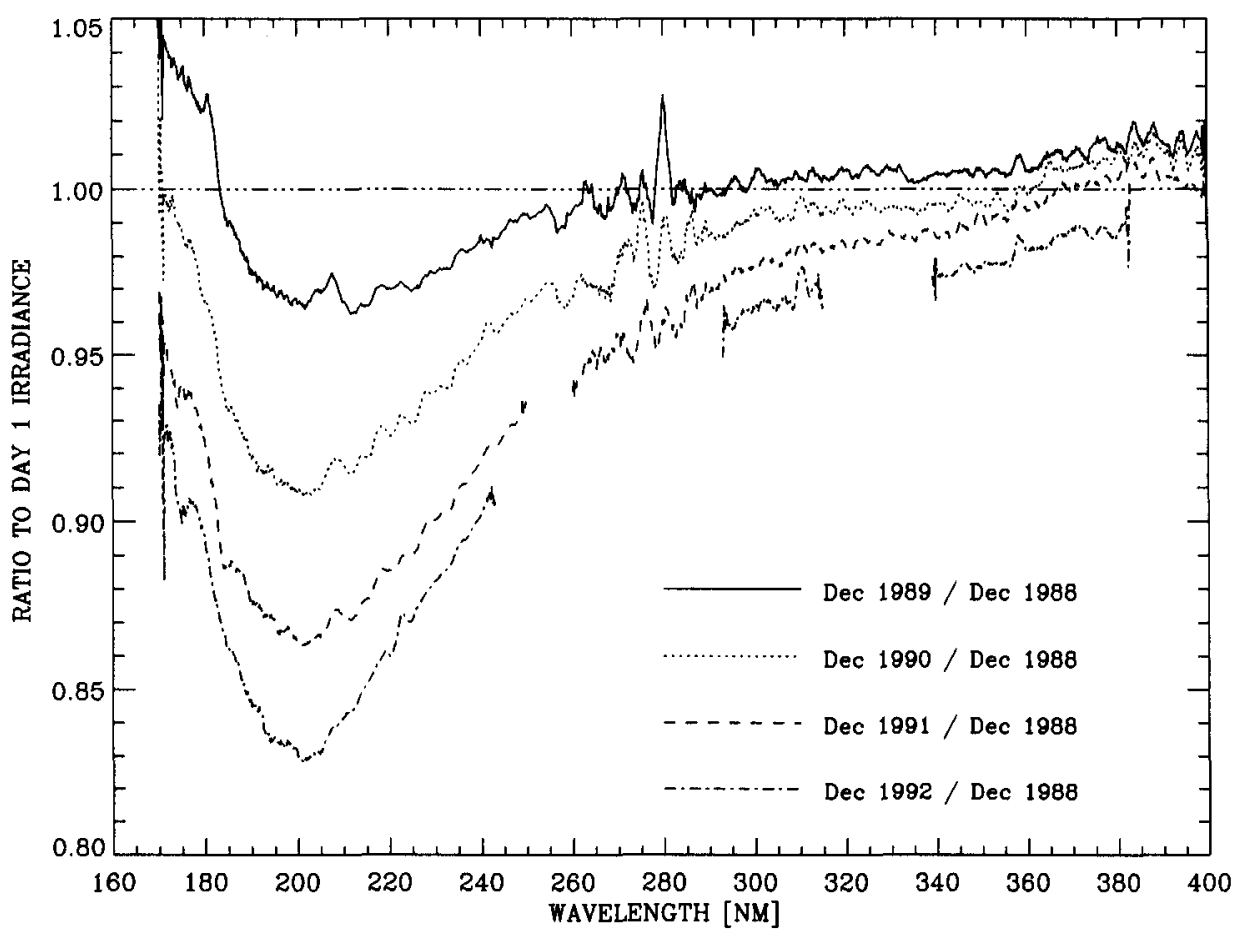

FIgURE 3. Annual comparisons of NOAA-11 SBUV/2 solar spectral irradiance measurements to the initial measurement.

SSBUV solar spectral irradiance data from the first four missions are compared in Figure 4. Each mission's data were processed using that mission's postflight calibration, since the postflight calibrations most accurately represent the instrument sensitivity on orbit (Cebula \& Hilsenrath 1992). Shortward of $260 \mathrm{~nm}$ the SSBUV-4 calibration is provisional. Middle UV solar activity, evaluated using 27-day averages of the $\mathrm{Mg}$ II index, varied by only $3 \%$ amongst the first four SSBUV missions. Therefore, we have not corrected for UV solar activity variations in this comparison. Longward of $300 \mathrm{~nm}$, where long-term solar changes are negligible, the peak-to-peak reproducibility of the SSBUV solar spectral irradiance is better than $1.5 \%$. The $\pm 1 \%$ spectral structure seen in the 220 to $290 \mathrm{~nm}$ region is indicative of a small error in the SSBUV-1 calibration, and closely parallels, although is an order of magnitude smaller than that mission's calibration changes.

The mission-to-mission spectral differences seen just shortward of the Al edge near 210 $\mathrm{nm}$ mimic the spectral shape of the $\mathrm{Mg}$ II proxy index scale factors (DeLand \& Cebula 1993), which is distinct from the spectral shape of SSBUV calibration changes (Cebula \& Hilsenrath 1992), and therefore are indicative of true solar spectral irradiance variations from October 1989 through March 1992. Cebula \& Hilsenrath (1993) showed a $1 \%$ agreement between the solar spectral irradiance changes measured by SSBUV between October 1990 and August 1991 and the changes predicted by the $\mathrm{Mg}$ II index and scale factors. The Mg II indexes measured by SSBUV and NOAA-11 SBUV/2 show excellent agreement. 


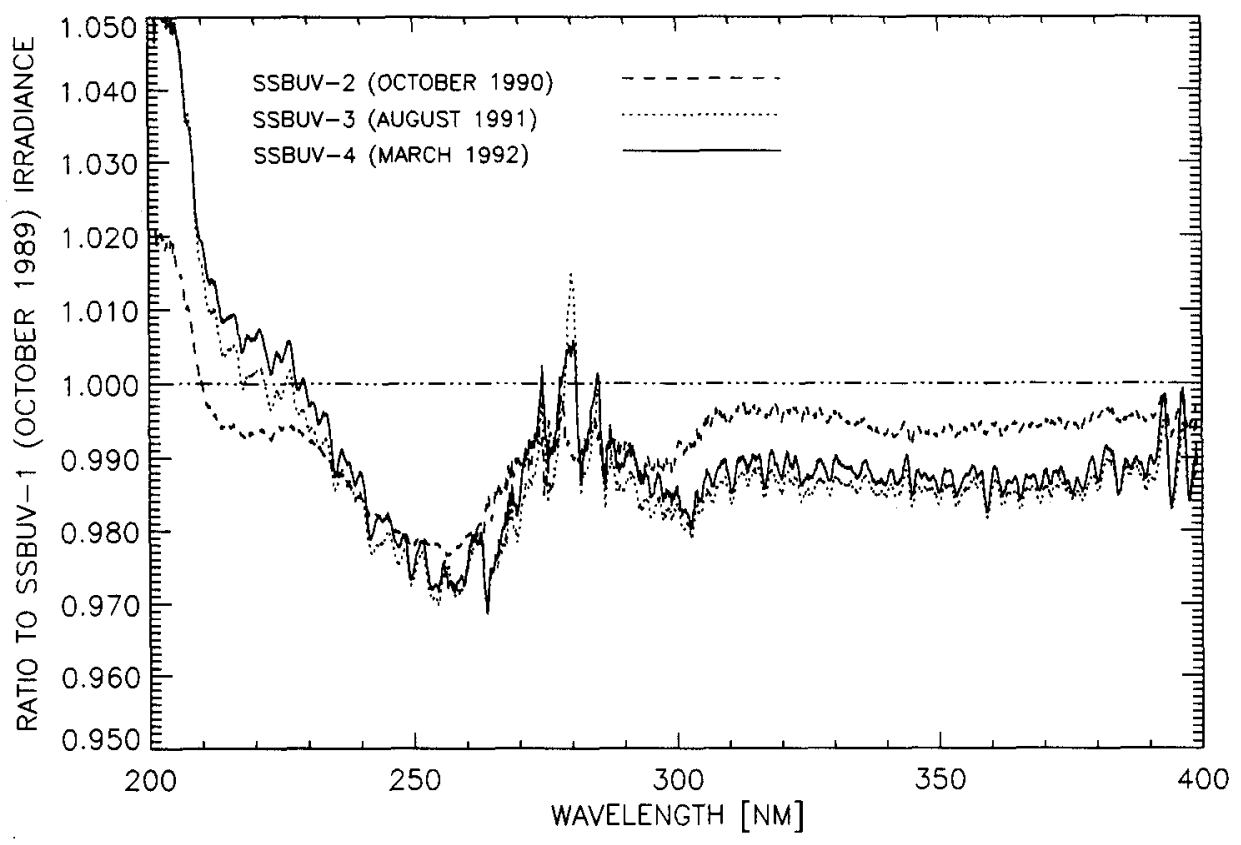

FIgURE 4. Ratios of the SSBUV-2, -3 , and -4 solar spectral irradiance measurements to the SSBUV-1 measurement. No correction for solar irradiance variation was made in these comparisons.

\section{Inter-instrument comparisons}

The initial solar spectral irradiances measured by the two satellite instruments and SSBUV are compared in Figure 5. Whereas the first NOAA-11 and the SSBUV-1 measurements were made near the peak of solar cycle 22 , NOAA- 9 began solar observations at solar minimum. In making this comparison we have corrected for long-term solar variation using the composite $\mathrm{Mg} \mathrm{II}$ index and associated scale factors. As discussed in DeLand \& Cebula (1993), noise in the raw SBUV/2 data gives rise to an approximate $1 \%$ noise in the $\mathrm{Mg}$ II index, and caution must be exercised in using individual $\mathrm{Mg}$ II index measurements. The solar change corrections used here, $5.5 \%$ for March 1985 to October 1989 and $1.5 \%$ for February 1988 to October 1989, are 1.5\% less than the corrections derived using the Mg II index. The solar spectral irradiances measured by these instruments agree to within -5 to $+10 \%$ between 200 and $400 \mathrm{~nm}$. The NOAA- 9 irradiance has a calibration-induced anomaly near $232 \mathrm{~nm}$ relative to the other instruments; this feature will be reduced once the instrument's calibration is revised. Longward of 250 $\mathrm{nm}$ the NOAA-9 and 11 and irradiances are larger than the SSBUV irradiance. The NOAA-9 irradiance shows a clear bias with respect to the other instruments above 360 $\mathrm{nm}$. The commonality of the two curves between 200 and $250 \mathrm{~nm}$ in Figure 5 signifies that the SSBUV irradiances are biased with respect to the two satellite instruments in this region. We plan to further investigate these differences via comparisons of these data with SOLSPEC, SOLSTICE, and SUSIM solar irradiance data.

Figure 6 presents the ratio of the NOAA-11 and SSBUV solar spectral irradiances for each of the first four SSBUV missions, relative to the Day 1 comparison. This pre- 


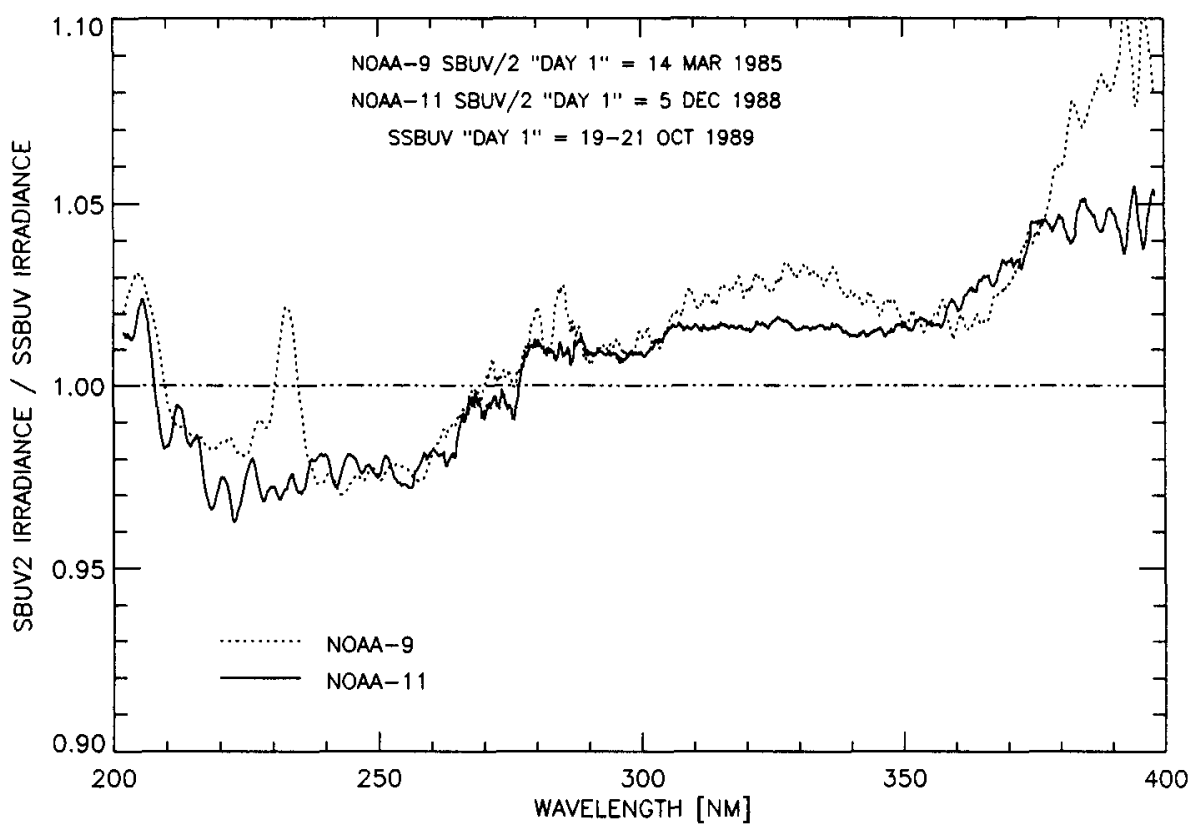

Figure 5. Ratios of the "Day 1" NOAA-9 SBUV/2 (dotted curve) and "Day 1" NOAA-11 SBUV/2 (solid curve) solar irradiances to the SSBUV-1 solar irradiance. These data were adjusted for solar variation.

sentation removes irradiance differences due to absolute calibration bias. As discussed previously, the satellite data were corrected for diffuser plate degradation but not for changes in the throughput of the monochromator. These comparisons indicate a significant spectrally dependent drift in the NOAA-11 instrument's sensitivity over four years, ranging from less than $1 \%$ near $400 \mathrm{~nm}$ to approximately $20 \%$ near $200 \mathrm{~nm}$. The SBUV $/ 2$ drift assessment presented in Figure 6 and the internal assessment presented in Figure 3 exhibit excellent agreement and indicate that SSBUV solar data can be used to monitor and correct for changes in the radiometric sensitivity of the SBUV/2 instruments, particularly at wavelengths shortward of $300 \mathrm{~nm}$, where long-term solar spectral irradiance changes are significant.

\section{Conclusion}

The SBUV / 2 instruments onboard the NOAA operational satellites provide high quality daily measurements of the middle UV solar spectral irradiance, however protracted instrument changes prevent these data from being directly used to assess long-term solar change. The SSBUV experiment provides solar spectral irradiance measurements which are accurate with respect to one another to within $\pm 1-2 \%$ from 200 to $400 \mathrm{~nm}$. Although each SSBUV mission provides only a snapshot of the solar output, the work summarized in this paper shows that SSBUV data can be used in conjunction with the simultaneous $\mathrm{SBUV} / 2$ data to assess both short and long-term solar spectral irradiance variations. Our ultimate goal is to combine the SSBUV-corrected solar data from NOAA-9 and 


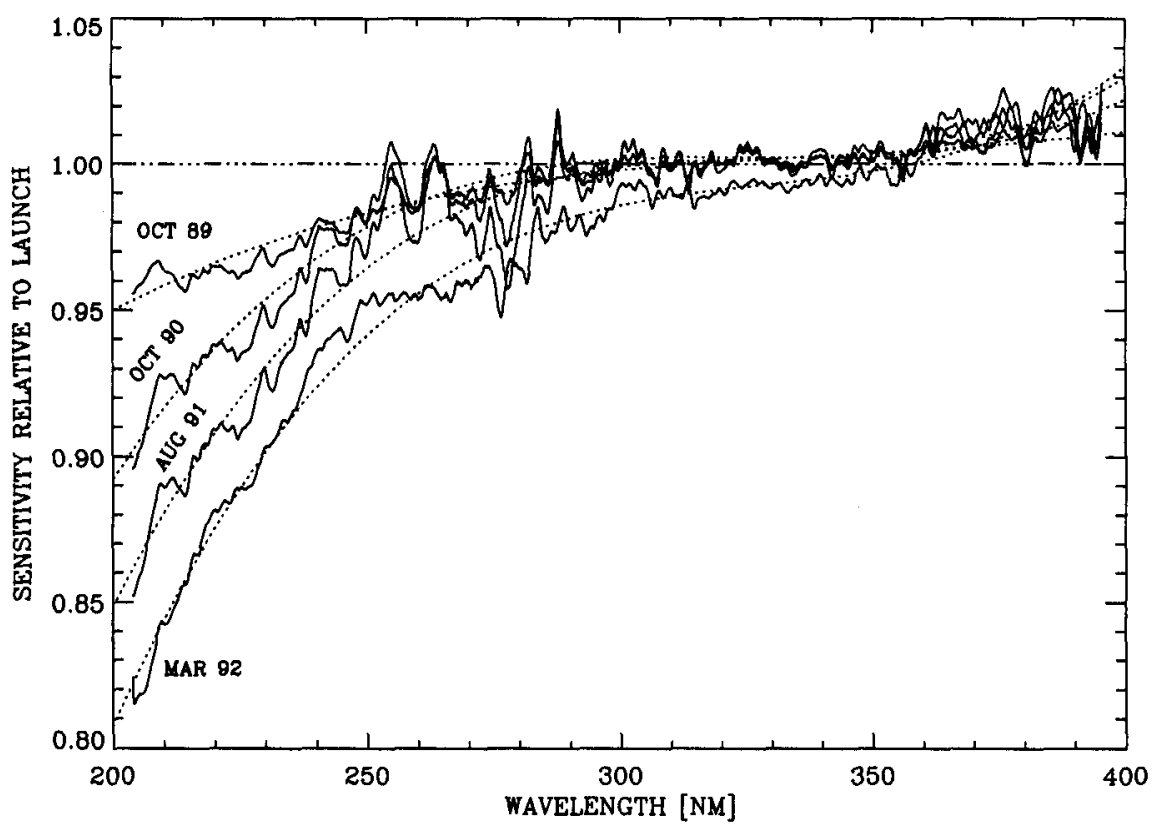

FIgURE 6. Ratios of the NOAA-11 SBUV/2 and the SSBUV solar spectral irradiances, October 1989 through March 1992, relative to the "Day 1" comparison. These curves provide a measure of the long-term drift in the satellite instrument. The smooth curves represent third order polynomial fits to the data.

NOAA-11 SBUV/2 with Nimbus-7 SBUV solar data to produce a single, self-consistent middle UV solar spectral irradiance data set covering the period 1978 through at least 1992.

Acknowledgments. This work was supported by NASA contract NAS5-31755. The SBUV $/ 2$ data were provided by H. D. Bowman, J. H. Lienesch and W. G. Planet of NOAA/NESDIS.

\section{REFERENCES}

Cebula, R. P. \& Deland, M. T. 1992 The SBUV/2 monitors on the NOAA-9 and NOAA-11 satellites. In Proceedings of the Workshop on the Solar Electromagnetic Radiation Study for Solar Cycle 22 (ed. R. F. Donnelly). pp. 239-249. NOAA ERL SEL, Boulder, CO, USA.

Cebula, R. P., Deland, M. T., Hilsenrath, E., Schlesinger, B. M., Hudson, R. D. \& HEATH D. F. 1991 Intercomparisons of the solar irraddiance measurements from the Nimbus-7 SBUV, the NOAA-9 and NOAA-11 SBUV/2, and the STS-34 SSBUV instruments: A preliminary study. J. Atmos. Terr. Physics 53, 993-997.

Cebula, R. P., Deland, M. T. \& Schlesinger, B. M. 1992 Estimates of solar variability using the Solar Backscatter Ultraviolet (SBUV) $2 \mathrm{Mg}$ II index from the NOAA-9 satellite. J. Geophys. Res. 97, 11613-11620.

Cebula, R. P. \& Hilsenrath, E. 1992 Ultraviolet solar irradiance measurements from the SSBUV-1 and SSBUV-2 missions. In Proceedings of the Workshop on the Solar Electro- 
magnetic Radiation Study for Solar Cycle 22 (ed. R. F. Donnelly). pp. 250-264. NOAA ERL SEL, Boulder, CO, USA.

Cebula, R. P. \& Hilsenrath E. 1993 SSBUV middle ultraviolet solar spectral irradiance measurements. In Proc. of the Quadrennial Ozone Symposium, in press.

Deland, M. T. \& Cebula, R. P. 1993 Composite Mg II solar activity index for solar cycles 21 and 22. J. Geophys. Res. 98, 12809-12823.

DonNelly, R. F. 1990 Solar UV temporal variation during solar cycle 22 and the twentieth century. In Climate Impact of Solar Variability (ed. K. H. Schatten \& A. Arking). NASA CP-3086, 328-335.

Frederick, J. E., Cebula, R. P. \& Heath D. F. 1986 Instrument characterization for the detection of long-term changes in stratospheric ozone: An analysis of the SBUV $/ 2$ radiometer. J. Atm. Oceanic Tech. 3, 472-480.

Hilsenrath, E., Williams, D. \& Frederick, J. 1988 Calibration of long term data sets from operational satellites using the Space Shuttle. In Proc. SPIE 924, 215-222.

Schlesinger, B. M \& CebulA, R. P. 1992 Solar variation 1979-1987 estimated from an empirical model for changes with time in the sensitivity of the Solar Backscatter Ultraviolet Instrument. J. Geophys. Res. 97, 10119-10134.

Weiss, H., Cebula, R. P. Laamann, K. \& McPeters R. D. 1993 Performance evaluation of the Solar Backscatter Ultraviolet Radiometer, Model 2 (SBUV/2) inflight calibration system. In Proc. of the Quadrennial Ozone Symposium, in press. 